\title{
Creo
}

Yo creo firmemente que tortuosos como parezcan los senderos de hoy, nos llevan, sin embargo, hacia la realización del reino ideal. Creo que nuestra tarea es la de disminuir los dolores inútiles y aumentar la concordia y el amor entre los hombres. No expreso nada nuevo. Repito en burdo lenguaje una lección que unos desdeñan, otros no comprenden y algunos olvidaron. Pero me bastaría para juzgar que no he vivido este día en vano, que uno solo de los oyentes, uno solo de los jóvenes que me escuchan, acordase la voz de su íntimo yo con esta mía, e hiciera de su juventud un estandarte de cruzado, en la lucha perenne por un reino mejor.- A M A N A $L$ A B A R A $H$.

\section{LA VERDAD DEL VIAJERO}

I

毁 $A$

verdad, sí. La verdad, que es mucho más fácil que la mentira. Para decir mentira hay que inventar. Si no, lo cogen a uno. El que dice mentiras sin inventar es, genéricamente, un tonto. ¡Si lo sabré yo, andaluz! El andaluz no miente. Exagera. Es imaginativo, sonoro y fino, como llamaba Rubén Darío, es decir, que vibra ante la más leve vibración que se produce fuera de él. Y vibra como una cuerda de guitarra, ampliando, extendiendo. De ahí, lo que cuenta un asturiano como cinco, lo cuenta un andaluz como diez. Pero después de todo esto, es tan fácil decir la verdad, que apenas se incomoda uno para exponerla. Yo no hubiera aceptado el simpático encargo de escribir, para esta especial ocasión, si no hubiera pensado desde el primer momento decir la verdad. Allá los que quieran, respondiendo a entrevistas deshilvanadas, verter elogios a granel y luego, al salir, decir lo contrario. La verdad, aunque, claro está, la verdad del viajero.

Yo sabía cosas de Chile, mucho antes de pensar en venir. Mucho antes de estudiar esa geografía elemental que dice, sin verdad, por supuesto, que después de la capital, las principales ciudades son Antofagasta, Coquimbo y Valparaíso, por este orden. Lo recuerdo perfectamente, desde aquellos nueve o diez años míos. Sabía mucho antes, por la sencilla razón de que en 
mi casa, en el balcón más céntrico, allá en el paseo frontero al puerto mediterráneo natal, ondeaba con frecuencia la bandera chilena. A mí me gustaba ayudar al criado a izarla, y después, me quedaba asomado un rato largo (los labios me llegaban a la altura de la baranda), para ver el efecto que producía en los niños que pasaban por la calle aquella bandera grande, con sus colores tan aptos para conmoverse debajo del cielo de mi tierra, oreada por la brisilla del mar. Empecé a coleccionar sellos de correo y tuve páginas y páginas de mi álbum llenas de los de Chile. Aquellos sellos grandes, con las batallas pintadas, con aquellos caballitos blancos y negros tan bien dibujados, me seducían. Y los otros, los que tenían retratos de Colón, con un bonete, que se me antojaba un cura; y un caballero de bigote cano, debajo del que ponía: Bulnes. Y un militar con patillas que se llamaba O'Higgins. Yo arrancaba estos sellos apenas llegaban los grandes paquetones de un periódico que me aburría, pero que mi padre hojeaba siempre: el Diario Oficial de la Repríblica de Chile. Y en el despacho de él, (aquí se diría despacho por una tienda, ya lo sé; y tienda por otra cosa, también lo sé), campeaba un retrato fotográfico, de perfil, dedicado y firmado. Nunca me acordaba del nombre, ni podía descifrar las letras, pero todos los días lo preguntaba: ¿Cómo se llama ese caballero»? y me respondían: "No dés la lata. Se llama don Pedro Montt».

Mi padre fué Cónsul de Chile en Málaga. No recuerdo si cónsul o vicecónsul, pero él mandaba más. Esto era lo in teresante para mí, en esos días. Que mandara más. Y en algunos ceremoniosos días, recuerdo que al salir con su sombrero de copa, repetía: ¿Han colocado la bandera de Chile en el balcón? Y yo quería, sin más razones, a Chile, más que a ninguna otra nación del mundo, después de España, y cuando jugábamos a los soldados, una pequeña banderita de Chile se colocaba junto a la española en mi campo de batalla. Leía yo por aquel entonces una novela grande que estaba encuadernada por entregas en la biblioteca de $\mathrm{mi}$ abuelo. El tomo era de 1868. La novela, que desde entonces no he vuelto a ver, se titulaba: "Aventuras y desgracias de la señora Libarona en el Gran Chaco». Y traía estampas de familias de indios atacadas por un jaguar y muchas de un tal Ibarra, un hombre cruel, perseguidor de la señora Libarona y los suyos, atormentador sin piedad, decorado con unos grandes mostachos. Busqué en un mapa el Gran Chaco. Y me pareció, porque era un mapa físico, sin límites ni fronteras, que el Gran Chaco formaba un área de Chile. Y le 
pregunté a mi padre: ¿Son así las gentes en Chile, como este Ibarra»? Y siempre influyó en mí la respuesta: "Chile es la nación más civilizada de América del Sur». Esto se me quedó grabado y muchos años después, la idea estaba intacta, mientras yo cursaba las mediaciones del bachillerato.

Más tarde,-portaría yo unos catorce años-mi padre tuvo una acumulación de quehaceres, que le obligó a dimitir el puesto consular. Mi colección de sellos de Chile estaba bien completa. Y aquella bandera sirvió, para hacerme una capa de torero. Mi pasión de entonces. Torear. Usé mucho, en corridas de cornamenta de mimbre, aquella capa bien aireada por tantos días de fiesta, azul, blanca y roja. La estrella había desaparecido. Era un capote de corrida, de faena, duro, que no tuvo una sola rasgadura, a pesar de que yo toreaba metido en la cuna, es decir, entre los pitones. Llegó a servirme en alguna becerrada, ya con animalillos medio bravos, con los cuernos más chicos que los de la cornamenta de mimbre, pero con más empuje en la embestida. Me había acostumbrado al manejo de aquei capote, y hacía con él reboleras y verónicas. De este modo, la bandera de Chile me acompaño, como elemento esencial de mis diversiones, durante mucho tiempo. Hasta que me convencí de que los toros estaban un poco reñidos, en cuan to a tiempo, con el preparatorio de la carrera de leyes.

Esta es la verdad de lo que yo sabía de Chile-y ya era bastante-, en los días claros de mi niñez. Y cuando me dió por hacer los primeros versos, y por conocer nombres de gente que hiciera versos, o prosa y guardarlos en la memoria para repetirlos cuando llegara la ocasión, la literatura chilena me presentaba un panorama sobremanera corto. En un libro de trozos escogidos que guardaba desde el primer año, venían con el adjetivo "Chileno» entre paréntesis, después del nombre, unos versos, muy pocos. Y eran de Guillermo Matta, de Carlos Walker Martínez y de A. Blest Gana. Poco después odié a Guillermo Matta por un soneto a Pizarro, que descubrí por casualidad. No supe más de la literatura chilena en mucho tiempo.

$\mathrm{Y}$ al llegar a Madrid, cuando ya me creía un hombrecito culto, hecho y derecho, y cuando ya me sonaban a familiares Jorge Isaacs, Asunción Silva, Darío, Larreta, Acuña, Díaz Mirón, Gálvez, Herrera Reissig y Lugones, pensaba también en una poetisa portorriqueña llamada Gabriela Mistral de quien había conocido algunos versos. La verdad, creí mucho tiempo que Gabriela Mistral era de Puerto Rico. La verdad, no sé por qué, 
pero no podía añadir su nombre a los de Walker. Matta y Blest Gana, en cuanto a nacionalidad.

No hay más razón que la geográfica, quiero decir que yo no encuentro más razón que esa, para la indeterminación de la obra literaria chilena en Europa. Ahora ya hemos salido de esos años ligeros y volátiles de la niñez. La verdad del viajero es desde este momento una verdad más cercana, más precisa y mejor definida. Mientras cualquíer muchacho sabe por allá qué poetas son mejicanos, argentinos o uruguayos, se arma un batiburrillo en cuanto se refiere a este litoral del Pacífico. Y coloca sus nombres indistintamente, aquí o allá, y los fija, según su antojo, gratuitamente, en cualquier parte, donde le plazca. Hablo, por cierto, de aquellos como yo, que no disfrutasen de una honda cultura americana. Es decir casi todos, por culpa de la abundancia. Esta abundancia que hacía, cuando llegaba un libro de poesías hispanoamericano, decir: Otro más. Los conocemos....

La culpa de esto, ya lo sabemos todos, los de aquí, y los de allá, quienes la tienen. Esos libros de poemas macarrónicos que se imprimen a troche y moche, y que llevan, después de un fárrago insoportable de renglones rimados, un conjunto de opiniones de gente más o menos célebre sobre la obra del tal autor. No se puede tener idea de lo lamentable que resulta esa facilidad de opinar sobre una obra cualquiera, ante la sola petición del escribidor y poner un nombre que tiene cierta fama y consideración, bajo un elogio desmesurado, a un currinche sin importancia. Así, el camino está lleno de broza y es necesario pararse un poco a ver como sigue la línea, para no abandonarlo y echar por otro. Creo también, que la falta de comunicación comercial inmediata debe influir mucho en este desconocimiento $y$ en esta mezcla de criterios. Es raro, pero cuando uno tiene más o menos al dedillo la literatura europea, proporcionalmente conoce nombres del lado del atlántico y sabe ubicarlos en su sitio correspondiente. Exceptuando a individuos del tamaño de un Montalvo, por ejemplo, lo demás se confunde, y es difícil delimitar quien es peruano, chileno, ecuatoriano, colombiano, si no se preocupa uno de averiguarlo particularmente. Si no quisiera decir la verdad del viajero, diría en este momento algo muy latiguillesco, algo muy oratorio. Los caminos del acercamiento espiritual están abiertos y grandes... etcétera. Pero rehuyo la oratoria decimonónica. 
Confieso con toda ingenuidad que al llegar aquí, sólo conocía dos o tres nombres de la literatura nacional. (Ya sé, ya veo algún crítico sagaz diciendo: «Qué ignorante!» Está bien). Estos nombres eran los de Armando Donoso y Eduardo Barrios, por haberlos visto en libros editados en España. Otro era el de Joaquín Edwards Bello. Alguien me prestó «El chileno en Madrid». El otro nombre que conocía, a través de lectura de escasos poemas, que me bastaron para comprender su valor, era Pablo Neruda. Advierto que este último me era conocido además porque se hablaba de él con harta frecuencia siempre admirativamente, excepcionalmente, en los grupos de amigos poetas de mi generación. Ninguno de nosotros le conocía personalmente. Sabíamos que estaba en Ceylán, y que era chileno. Y que su poesía era de la mejor poesía en español de nuestros días. (Ya sé que hoy es amigo mío. Lo advierto para salidas posibles. También soy amigo de un vecino comerciante en cereales y no puedo decir, por mucho que me esfuerce, que ès un poeta). Si se añade a estos nombres el de Vicente Huidobro, podemos parar de cuenta. Todo lo demás lo había visto por encima-y olvidado pronto-en Max Daireaux.

¿Por qué? Pregunto por qué no llega allí, con aviso y cartel, el resto de la obra literaria chilena. Por qué no se reparte-y si se repartiera bien, se vendería-la obra de otros escritores. Al decir el resto, no quiero expresar lo que sobra, sino lo que no se conoce. De esta labor si que debía ocuparse la sociedad de escritores. Labor de verdadera aproximación, de intercambio, y conocimiento. Sobre todo me refiero a ese sector de puro tuétano americano, interesante para la demostración de un pueblo. A lo directamente inspirado en la tierra.

\section{III}

Impresión de llegada. Son raras las ciudades que tienen las estaciones de ferrocarril en buena situación de salida. Para un Quai d'Orsay existen en París una Gare de l'Est y una Gare du Nord que desembocan en sectores de escasa belleza. Salir de la estación Mapocho y meterme corriendo, al camino rápido del taxi, por una serie de calles con poca luz, me llenó de tristeza. Era de noche, venía cansado y a pesar de todo salí a pasear un poco. La impresión fué de franca simpatía. i «Pero qué andaluz es esto»!, me iba repitiendo para mis adentros. Se me antojaba estar en un Cádiz, más grande, con más anuncios luminosos y mejores edificios. Fué un trecho céntrico el que recorrí y que- 
dé satisfecho. Me gustaba. Al día siguiente, a pleno sol en alto, volví a salir a la calle. Naturalmente no conocía a nadie. Pero me pareció que conocía a muchos. Parados en una esquina veía al general gobernador de Málaga, charlando con un tío mío. Más allá encontré a mis primas. Al comprar cigarrillos descubrí el dueño del estanco de calle de las Sierpes, en Sevilla. Tomé un taxi y el conductor me pareció el mismo que me había llevado a la estación en Madrid. No me hubiera extrañado encontrarme al Duque de Alba y al jefe de la minoría radical-socialista del parlamento español. Pregunté por una calle y me la señalaron amablemente. En Andalucía tal vez me hubieran acompañado hasta la propia calle. Pero eso está un poco demás. Lo único que notaba diferente, que me hacía trasponer la idea de extranjería, era que todos los que escuchaba, me hablaban con un tono demasiado melifluo, para mis oídos acostumbrados a lo duro. Fuí a comprar un periódico y el chico que me lo vendió se llevó en pago, además de su precio, un magnífico pañuelo de seda que ostentaba con orgullo mi bolsillo pectoral. ¡Hombre!

Y me sentía bien. ¿Qué calma! De repente, unos aeroplanos comenzaron a zumbar por encima de mi cabeza. La gente se paraba y los miraba riendo. "Estarán haciendo prácticas», me dije. Pero escuché algún comentario. "Van a tomarse la Moneda. Son los de la escuela de aviación»... ¿La Moneda? ¿Cómo será eso? ¿Qué los aviadores quieren tomarse la moneda? A lo mejor yo no entiendo tan bien como me imaginaba este lenguaje. Volví al hotel, desasosegado. ¿Qué es la moneda? ¿Quieren decirme, por favor?... Y me enteré de que era el palacio presidencial. Y ví que había revolución. ¡Diablos! Mi padre me decía que aquí nunca había revolución, que esto era un ejemplo de orden y firmeza. Volví a salir y vi soldados de caballería, lanceros, mejor dicho, patrullando. Me dijeron que eran carabineros. ¿Carabineros? ¿Algo de contrabando, quizá? Estaba hecho un lío. Decidí irme al hotel. Cerca de él, pasó rozándome un auto magnífico, con una sirena desconcertante. Me dí cuenta de que era una ambulancia. Una ambulancia como he visto pocas, de comodidad y lujo, en todo el mundo. Al entrar en mi habitación ví el almanaque: ¡Cuatro de Junio! Llegar a Santiago y sentir el virus revolucionario fué todo uno.

Pero dejemos esto. Para huir de la cotidiana discusión política, no hay mejor medio que asomarse al paisaje. La salvación está en el paisaje. Mirando, desde la azotea del hotel, la cordillera nevada, se me alejó, por puente de plata la idea de que algo se conmovía en la ciudad. Así como Dostoieswky, decía, mirando una noche blanca: «Pero es posible que bajo tan bello dosel 
vivan seres llenos de perversidad y malicia?» yo pensaba que parecía imposible que existiendo terrazas frente a aquel paisaje hubiera quién se preocupara de algo más. Mal sistema, si queréis, en política. ¡Cristo! ¡qué montañas!. . Mi ojo estaba acostumbrado a los horizontes cambiantes, de serranía y llanada, de verde y pardo, al monte pelado y a la huerta estallante de brillo. Pero no conocía esta mole extensa, compacta, suave en su grandeza, caída en dejadez solemne. Me venía el pensamiento de que tenía que hacer algo y lo desechaba. Allí estaba toda mi vista concentrada, diluyéndose, sin saber qué hacer, recogida en un campo de nieve ondulada, en una roca gris, en la nube que se enganchaba los jirones más bajos en los picos más altos. ¿Hubiera querido un horizonte más extenso? Quizá se me ocurría, pero para qué más extensión que el resbalar por planos de cristal, ski de $\mathrm{mi}$ vista, bobsleigh de mis dos ojos equilibrándose en las andanadas, conteniendo la respiración en las caídas presurosas. Ya lo sabía yo. Si me iba mal en ciertos días, con quedarme al caer la tarde, mirando un rato la cordillera, estaba todo arreglado. $\mathrm{Y}$ me hice íntimo amigo del gigante, y desde entonces nos hemos ido tomando confianza. Salvando las diferencias por supuesto.

Supuse que los habitantes se pasarían el tiempo deseando escalar las montañas, pisar su nieve, asomarse a sus barrancos y ascender a lo alto, mirando al otro lado de la cadena. Me imaginé caravanas extensas, dominicales y llenas de aire limpio, camino de la montaña. Pensé adherirme inmediatamente a estas gentes. Vivir aquí y tener impulsos de subir, debe ser todo uno. Y pensé que a la grandeza que repartía el paisaje, debía corresponder una grandeza artística por igual, amplia, abierta y gigantesca.

\section{IV}

Hace bastantes años, cuando las revistas publicaban unas historietas fotográficas, reales, con un mismo personaje en varias actitudes, diciendo sandeces más o menos preparadas (Nadar, fué un prodigio en esta producción), se estilaba también sacar confesiones a las celebridades, sometiéndolas, antes de que naciera la entrevista, a un cuestionario impreso, con espacios de puntos suspensivos para la respuesta. De todo ello, al ser devuelto, se hacía un cliché y se publicaba. A todos le preguntaban lo mismo. ¿Qué color prefiere? ¿Cuál es su flor predilecta? ¿Qué tipo de mujer le gusta más? ¿Si no fuera usted francés (o tártaro) que le gustaría ser...? Respondían el biólogo, el pintor, el político, el poeta y la cortesana, todos por el mismo modelo. 
Cosas del siglo que terminaba. Cosas de aquella centuria que inspiró a Bretón de los Herreros:

Oh, siglo del vapor $\mathrm{y}$ del buen tono;

Oh venturoso siglo diecinueve,

O por mejor decir, decimonono......

Pues bien, esas preguntas se me podían haber hecho a mi al llegar a Chile u otras por el estilo. Pongámonos a la altura de las fotografías de Nadar y de las encuestas de la «Vie Heureuse». Si me hubieran preguntado al día siguiente:

P.-¿¿Qué es lo que más le impresionó a usted al llegar a Chile?

Yo.-La cordillera y las mujeres. O si quiere, mejor, las mujeres y la cordillera.

P.- ¿Qué efecto le hizo a usted la llegada?

Yo.-La cordillera y las mujeres.

P.- ¿Cómo encuentra usted la literatura chilena?

Yo.-La cordillera y las mujeres.

P.- ¿Quiere decirnos algo sobre su idea hispanoamericana?

Yo.- Me gustan las mujeres chilenas y la cordillera.

$\mathrm{Y}$ así una página. Ustedes sabrán perdonarme. Ignoraba casi todo.

Pero el redactor ha regresado con una sola de las preguntas, en vista del fracaso que han tenido las demás, en su apreciación. Esa pregunta es: ¿Cómo encuentra usted la literatura chilena?

Ni yo soy crítico ni quien tal vió, para abarcar en un golpe de vista todo un panorama literario. Ni podría, por cierto, hacer un recuento completo de valores, ya que mi conocimiento al llegar era escaso, y lo que he conocido después, si bien he ido procurando apreciarlo todo, no me da motivos para hablar en general. Elementalmente, hallé una cosa. Personal si se quiere, o extraliteraria, pero íntimamente ligada con la literatura. La cordialidad. Quizá con una rarísima excepción, a lo más dos excepciones, he hallado en los escritores chilenos una falta de postura literaria, una sencillez afable en el trato, una simpatía extraordinaria que me hizo apreciarlos desde la primera topada.

Después, ya entrando en la materia, puedo decir, resumiendo, y a grandes saltos: que no pretendo sentar cátedra ni adoctrinar, porque ni puedo, ni tengo pretensiones de poder hacerlo. Voy a decir lo que me parece bien y lo que me parece mal. Sin paliativos en ningún orden, ajustándome a la verdad del viajero.

Mas jay! (qué diría Fernández y González) la cosa presenta peligro de aburrimiento. Hay un cartel con dos piernas cruzadas y una cabeza soñolienta que dice: No tocar este tema; peligro de pesadez. Veo el letrero y me quedo desorientado. Sin norte, sin 
sur, sin este, y sin aquel. Si pudiera establecer aquí algo que me fué surgiendo por afán de síntesis, sin torcer ni un ápice mis pareceres, con respecto a los escritores franceses y españoles, a los mayores en años y en categoría viviente, a los que logré reducir a un cuadro nominal repetido, lo haría de buen grado. Clasificaba por esa casualidad simpática de los nombres, lo que más me placía entre ellos. En Francia, tres Paul, tres Marcel, tres André y dos Jean: Valery, Claudel, Morand; Proust, Prevost, Arland; Gide, Maurois, Rivoire; Giraudoux y Cocteau... Por lo que se refiere a esos mayores de edad en mi predilección literaria española, se reducía la sinopsis a un Miguel y cuatro Ramones: Unamuno; Valle-Inclán, Pérez de Ayala, Gómez de la Serna y (Juan) Ramón Jiménez. Pamplinas, al fin, pero pamplinas que resumen, entretienen y sobre todo, son verdad.

Para huir del cartel temeroso, quisiera resumir-es decir, daros el trabajo de resumir-las iniciales de los párrafos siguientes: El juego puede dístraer tanto como unas palabras cruzadas o un acertijo enrevesado. A continuación van unas frases, separadas por puntos y aparte; cogiendo las letras iniciales de cada una de estas palabras que forman cada párrafo, se obtendrá, al final de la cláusula, el nombre representativo de lo que dice la frase. En ellas van encerradas, por este truco, las figuras que me parecen bien de las letras chilenas. Y en el párrafo de donde hay que sacar las iniciales, la opinión que su obra me produce. Vamos al caso:

1. Poesía Alta. Belleza Lírica Optima. Nueva Expresión Romántica Universal. Designio Americano. (Hágasé el nombre con las iniciales. L̀o mismo en los que siguen).

2. Poder Expresivo Dominante. Reacción Ordenada Para Reglar Artísticamente Dominios Oscuros.

3. Variación Iconoclasta Constante. Espíritu Nunca Tardío. En Humanidad. Ultima Idea Destacada O Balbuceada Recogida Obligatoriamente.

4. Me Agrada Reconocer Indudables Aciertos, Numerosas Obtenciones; Los Ambientes Típicos O Regionales Resultan Ex celentes.

5. Jews Of América, Quacks, Ugly Indians, Naked Evil Devils, Were All Running, Dancing, Singing... (La pesadilla del autor!).

6. Recoge Ondas Supremas, Alturas Maravillosas, Elevaciones Luminosas. Desciende, Eliminando Lirismos Vacíos, A La Luz Enterrada.

7. El Romance Nativo Está Sabiamente Tratado. Original 
Manera Obtenida No Teniendo En Nimiedad El Germen Racial Olvidado.

8. Aunque Numéricamente Tiene Obra, No Intentemos Ordenarla. Avanzando, Conseguirá Escribir Victoriosamente El Drama Oligárquico,

9. Escritor De Una Atrayente Rudeza Dominada. Otro Buen Ambientador. Resulta Romántico, Incluso Obstruyendo Sentimentalismos.

Aquí termino la lista de las averiguaciones. Y debiendo terminar del todo, para que el cartel no vuelva con sus colores a peripatear ante mis ojos, no lo haré tan inmediatamente que me quede sin desembuchar algunas apreciaciones - o depreciaciones - que vienen como el anillo al dedo. Una de ellas, que no requería mayor tormento explicativo, es la determinación de lo que me interesa, es decir: la juventud, la novedad. No por nuevo y joven, sino por oposición a lo caduco y agonizante. Caducar no es pasar, puesto que ya sabemos cuantos viven y seguirán viviendo por encima del tiempo. Es simple cuestión de interés. De los nombres que forman los juegos de palabra antecedentes, los que me interesan son los que representan una auténtica ju-. ventud. Los otros me podíán parecer más o menos apreciables. Lo mismo acontece con esos nombres de franceses y españoles que cité. Me parecen bien, pero interesarme, a lo mejor me interesan menos que un Ribemont- Dessaignes o un Bretón. A pesar de ser surrealistas. Bueno; es el caso, que el viajero se ciñe de nuevo a la verdad y declarando su interés por la juventud literaria chilena, admirando algunos de sus componentes lo más posible, halla en ella una falta de cohesión, de ánimo y de ganas de trabajar (literariamente) deplorables. La juventud tendría que comenzar a moverse y a empujar, levemente, suavemente al menos, para que se deshiciera la arcilla incoherente de algunos ídolos mal amasados. Por desgracia, no existen en ella estas cualidades, salvo escasas, escasísimas excepciones. Teniendo gentes de gran talento y de extraordinaria sensibilidad, pierden su fuerza los hechos por el solo placer de estarse quietos.

Hay dos estatuas en Santiago que representan claros varones de la historia nacional, meritorios y dignos, pero cuya factura en piedra o bronce, su colocación decorativa, me sugiere comparaciones. La una está situada enfrente del Palacio de los Tribunales y la otra cerca de la Universidad, mirando Alameda abajo. De esos claros varones hay en cada estatua uno sentado y otro de pie. Apenas un espacio mínimo permite al sentado estirar sus piernas y al que está de pie variar de postura. Y se me antoja que los dos que permanecen levantados, piden con todas las ve- 
ras de su alma al del sillon que les ceda un momento la comodidad, que les deje desperezar un rato sus músculos, porque van a caer abajo de un momento a otro. El que está sentado se hace el sordo. Y así, en equilibrio casi indiferente, se mantienen desde hace años y se mantendrán mucho tiempo. Excluyo completamente todo nombre de conmemoración o alusión directa a lo que representan las estatuas. No me refiero a los patricios glorificados sino a la factura que dí́ el escultor (y luego amplió el arquitecto) a esos monumentos representativos. La angustia que me produce pensar que los del alto pedestal fueran de carne y hueso, se me hace palpable y se me aparece como un ejemplo bien claro de dos generaciones literarias chilenas. Hay que dar al traste con algo para quedar cómodos. Para descansar hay que conquistar antes el sitio apacible y grato.

\section{V}

Poco después de llegado contemplé (incluso tomé parte en ella) una polémica o curso de opiniones sobre la crítica literaria. Propiamente no tuvo carácter polémico, pues la diversidad de criterios no llegó a enfrentar. Hoy, pasado algún tiempo, mantengo posiciones generales que ocupé. Mas, como no era aquello sino una vista de conjunto, y apenas rocé la visión particularista, añado un colofón a lo mantenido. He ido notando en algún representante de esta crítica una posición de independencia que me admira. En otros, una buena voluntad que me subyuga. Me doy cuenta de que no es tan fácil hacer una crónica de libros nacionales como antes pensaba que fuera. La situación del crítico, sin cambiar elementalmente para mí, ha variado en accidentes de innegable apreciación. Lo que no llego a comprender es que se tenga la necesidad de criticarlo todo; de ensartar un largo artículo para comentar una porquería escrita. Mi extrañeza fué de ese aspecto. Creía que para criticar se necesitaba interesarse por lo criticado, o pasar de largo. De ahí vienen la mayoría de las equivocaciones. Recientemente, un escritor, crítico, dedicó un largo artículo a comentar un libro que él llamaba el peor libro del año. Al poco tiempo la empresa editorial anunciaba el libro diciendo: Por haber sido criticado de esa manera por el señor Tal, el libro Cual, comienza a venderse a granel. Supongo que no será cierto. En primer lugar, el libro, que leí a grandes saltos, me parecí́ no el peor del año, sino el peor de la década. O en la fila de los peores, que son muchos. En segundo lugar, el anuncio editorial me pareció absurdo. En tercero y último lugar, me pareció que el crítico no tenía necesidad de ocu- 
parse de semejante obra, ni de pergeñar dos renglones en su honor. Claro que este mismo crítico se ha extasiado ante poesías que son de lo peor de la centuria. De todo esto sale una desorientación espantosa. Debía de haber menos crítica de libros y menos críticos. Más selección para los aciertos y más desprecio para las pifias. Y sobre todo, jeso sí, por favor!, no se metan en cosas que salen fuera de una capacidad captadora. Si no se atreven a hacer una crítica de un tratado de Otorinolaringología o de Cálculo Infinitesimal, porque no entienden de eso, ¿por qué se meten a hacerla de poesía, pongo por caso? Viene a ser tan particular una cosa como las otras. Hay un crítico de poesía chileno (no escribe en los diarios, lo advierto) que él mismo se confiesa un poco retrasado ante el cambiante panorama literario del momento. Y, sin embargo, llena páginas de juzgamientos (juicios, no) acerca de la poesía de este momento cambiante. Es la cuestión del caballero sentado sobre la alta estatua. El que está de pie, que ve más lejos, por encima de los tejados, seguirá de pie mientras a su cofrade no se le ocurra levantarse.

\section{VI}

El viajero se calla. Y ahora recuerda, después de haber titulado a su artículo "La verdad del Viajero» que un compatriota y maestro suyo, José Ortega y Gasset dijo en una ocasión : «La verdad del viajero es su error». ¡Pámpanos! ¡No haberse acordado antes! Pero ya está hecho. Interprétenlo ustedes como quieran. A lo mejor todo es verdad del viajero en ese sentido. De un viajero que quiere a estas tierras entrañablemente, cada día más. Porque de ellas tuve lo mejor que podían darme: mi mujer. Y a este paisaje di lo mejor que podía darle yo: mi hijo. - J O S É M A R I A $S$ O U V I R O N.

\section{EL FRACASO DE LA DEMOGRAGIA}

DOSIBLEMENTE, cuando se plantea el problema tan discutido en nuestros días, del fracaso de la democracia, se olvida precisar lo suficiente que, en realidad, no se trata de negar que el pueblo deba gobernarse a sí mismo. Siempre será un principio fundamental que el gobierno debe ser del pueblo y que debe gobernarse para el pueblo. Pero, lo que ahora se discute es, en primer lugar, si la forma que tiene actualmente 